University of Nebraska - Lincoln DigitalCommons@University of Nebraska - Lincoln

Uniformed Services University of the Health

Sciences

U.S. Department of Defense

2016

\title{
Prurigo Pigmentosa: An under-recognized inflammatory dermatosis characterized by an evolution of distinctive clinicopathological features
}

Elizabeth Satter

Uniformed Services University of the Health Sciences

Christopher Rozelle

Uniformed Services University of the Health Sciences

Leonard Sperling

Uniformed Services University of the Health Sciences

Follow this and additional works at: http://digitalcommons.unl.edu/usuhs

Satter, Elizabeth; Rozelle, Christopher; and Sperling, Leonard, "Prurigo Pigmentosa: An under-recognized inflammatory dermatosis characterized by an evolution of distinctive clinicopathological features" (2016). Uniformed Services University of the Health Sciences. 182.

http://digitalcommons.unl.edu/usuhs/182

This Article is brought to you for free and open access by the U.S. Department of Defense at DigitalCommons@University of Nebraska - Lincoln. It has been accepted for inclusion in Uniformed Services University of the Health Sciences by an authorized administrator of DigitalCommons@University of Nebraska - Lincoln. 


\section{Cover Quizlet}

\section{Elizabeth Satter MD/MPH ${ }^{1}$, Christopher Rozelle MD² and Leonard Sperling MD ${ }^{3}$}

Figures 1 and 2 are depicted on the journal cover.

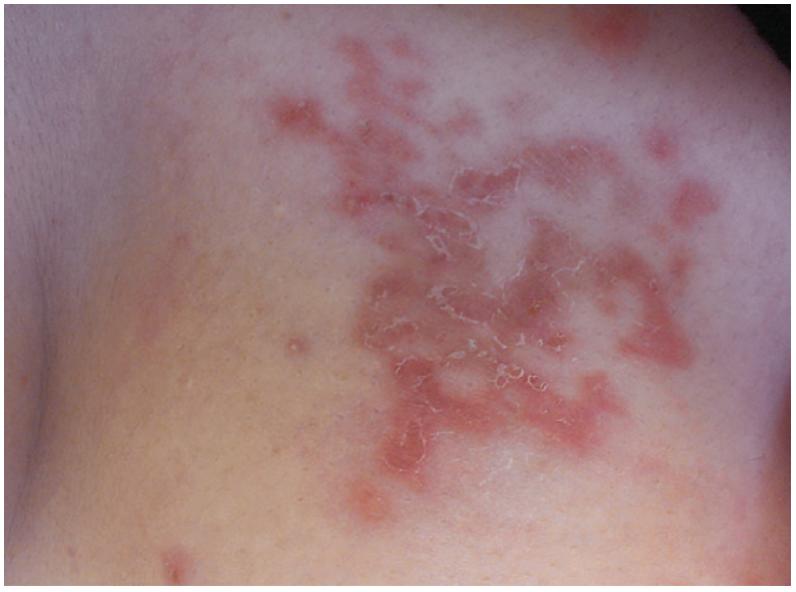

Figure 3.

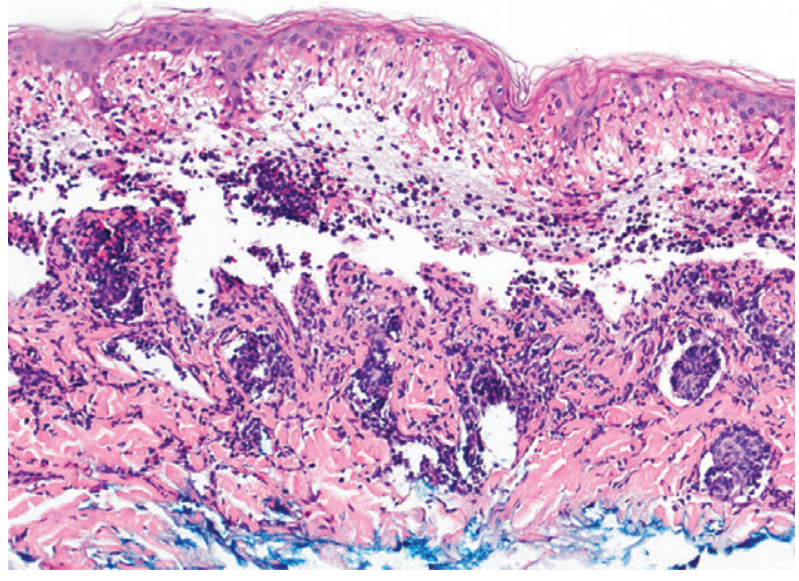

Figure 5 .

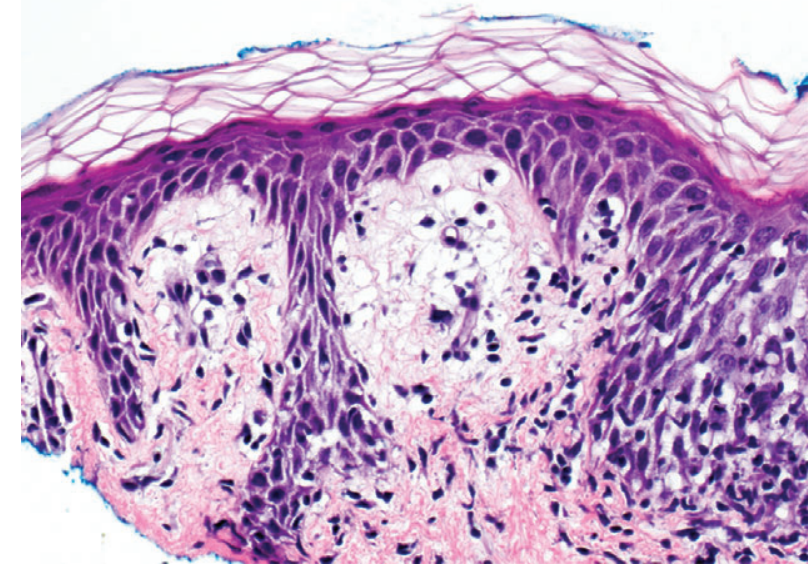

Figure 4.

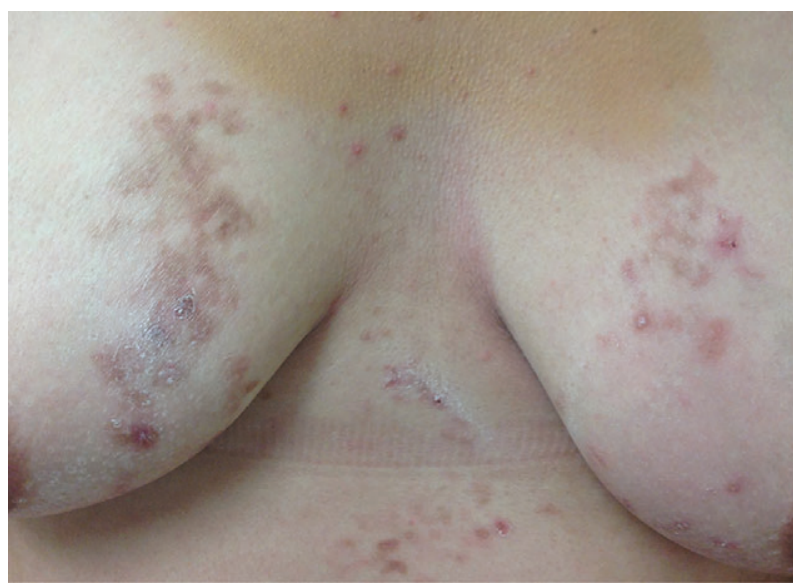

Figure 6.

Your diagnosis?

Continued on next page 


\section{Cover Quizlet}

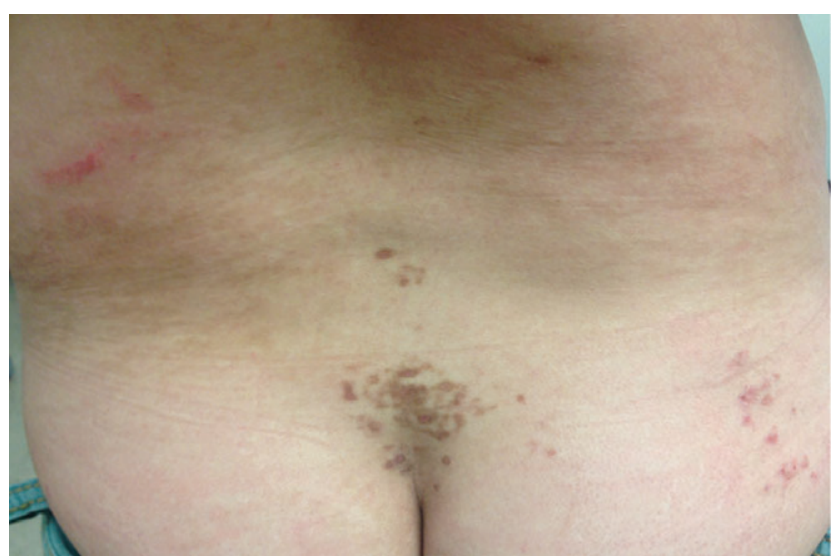

Figure 7.

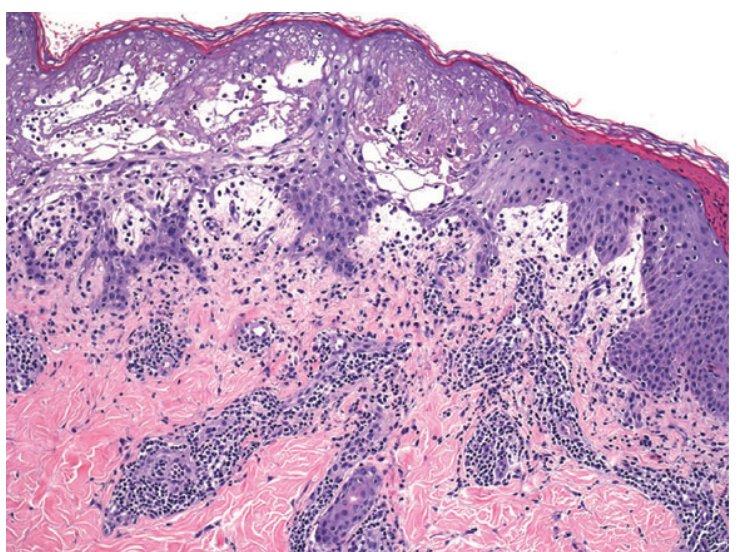

Figure 8.

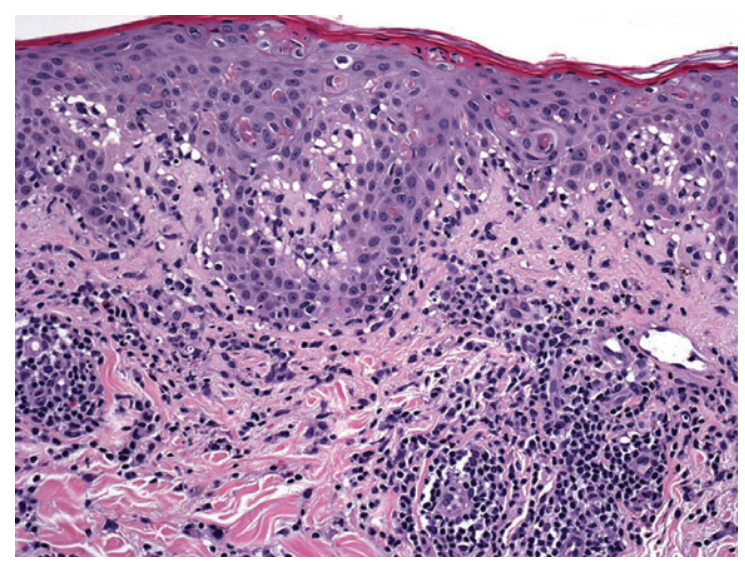

Figure 9.

Your diagnosis?

Discussion follows on page 811 


\title{
Prurigo Pigmentosa: An under-recognized inflammatory dermatosis characterized by an evolution of distinctive clinicopathological features
}

\author{
Elizabeth Satter MD/MPH' ${ }^{1}$, Christopher Rozelle MD² and Leonard Sperling MD³ \\ ${ }^{1}$ Departments of Dermatology and Pathology, \\ 2Department of Pathology, and \\ ${ }^{3}$ Departments of Dermatology and Pathology, Uniformed Services University of the Health Sciences, Bethesda, MD 20814, USA
}

E-mail: Leonard.sperling@usuhs.edu

Keywords: Prurigo Pigmentosa, inflammatory dermatosis, clinicopathological features

Accepted for publication June 20, 2016

Dr Satter, Rozelle and Sperling had full access to all of the data in the study and takes responsibility for the integrity of the data and the accuracy of the data analysis. Drafting of the manuscript and critical revision of the manuscript for important intellectual content was performed by Dr Satter, Rozelle and Sperling. Study concept, design and statistical analysis: N/A case report Interpretation of data: Dr Satter, Rozelle and Sperling. No administrative, technical, or material support was provided. No funding was obtained and the authors have no financial disclosures or conflicts of interest to report.

Prurigo pigmentosa (PP) was originally described 45 years ago, yet because of its variable histopathological manifestations it remains an under-recognized inflammatory dermatosis clinically characterized by recurrent pruritic, erythematous macules, urticarial papules and papulovesicles that eventuate in symmetric reticulated pigmentation. ${ }^{1}$ Although the majority of cases have been reported in women of Asian descent, it also has been described in various ethnicities worldwide. Of the approximately 400 reported cases of $\mathrm{PP}$, fewer than 10 have been reported from the United States. ${ }^{1-7}$

Due to the relative rarity of this condition, we present two cases from the United States to illustrate the clinicopathological spectrum of PP. Both patients were healthy young women who presented with recurrent episodes of pruritic erythematous macules and subsequently developed urticarial plaques, papules and/or papulovesicles which eventuated in reticulated pigmentation. The clinical and histological findings for these patients are summarized in Table 1.

Clinically PP presents as a recurrent intensely pruritic, symmetrically distributed eruption located on the neck, chest, upper back, lumbosacral region and abdomen, and more rarely, the forehead or arms. To date, there are no reports of mucous membrane involvement., The lesions tend to progress through several stages of development, initially starting as erythematous macules which then evolve to urticarial papules and papulovesicles. Subsequently the lesions become crusted or scaly and within a few weeks spontaneously resolve, leaving behind reticulated pigmentation. Due to the recurrent nature of the eruption, patients often have multiple lesions at various stages of development. ${ }^{1}$ The clinical differential diagnosis is broad, but the distribution of the lesions and the reticulated pattern helps narrow the possibilities. 
Table 1. Clinicohistopathological presentations of patients 1 and 2

Patient 1

\begin{tabular}{|c|c|c|}
\hline \multicolumn{3}{|l|}{ Clinical Findings } \\
\hline Ethnicity & Palestinian descent & Mexican descent \\
\hline Duration & 24-36 months & 29-months \\
\hline Anatomic location & Chest (Figs. 1 and 3) & $\begin{array}{l}\text { Central chest and breast (Fig. 6), flank, sacrum, } \\
\text { buttock (Fig. 7) and focally on left elbow }\end{array}$ \\
\hline Exacerbating factors & Pregnancy & Heat and exercise \\
\hline Serological findings & None & Elevated WBC with left shift \\
\hline Treatments & Minocycline-improvement & $\begin{array}{l}\text { Topical steroids-minimal benefit. } \\
\text { Minocycline-resolution }\end{array}$ \\
\hline \multicolumn{3}{|c|}{ Histopathological findings } \\
\hline Evolving lesion: & $\begin{array}{l}\text { Mild spongiosis, sparse perivascular infiltrate and } \\
\text { dermal edema. (Fig. 4) }\end{array}$ & \\
\hline Early lesions: & $\begin{array}{l}\text { Superficial dermal mixed inflammatory infiltrate } \\
\text { associated with neutrophilic spongiosis. (Fig. 2) }\end{array}$ & $\begin{array}{l}\text { Epidermal spongiosis associated with a } \\
\text { perivascular lymphocytic infiltrate and focal } \\
\text { vacuolar degeneration. }\end{array}$ \\
\hline Fully developed lesions & $\begin{array}{l}\text { Dense mixed dermal infiltrate associate with } \\
\text { combined balloon degeneration and spongiosis, } \\
\text { and clusters of necrotic keratinocytes. (Fig. 5) }\end{array}$ & $\begin{array}{l}\text { Brisk vacuolar degeneration with numerous } \\
\text { apoptotic keratinocytes often concentrated near } \\
\text { acrosyringium. Superficial perivascular } \\
\text { lymphocytic infiltrate with increased } \\
\text { eosinophils. (Fig. 8) }\end{array}$ \\
\hline Resolving/late lesions & $\begin{array}{l}\text { Mild spongiosis and a sparse perivascular } \\
\text { lymphocytic infiltrate. }\end{array}$ & $\begin{array}{l}\text { Parakeratosis, focal apoptotic keratinocytes, and a } \\
\text { superficial perivascular lymphocytic infiltrate } \\
\text { containing melanophages. (Fig. 9) }\end{array}$ \\
\hline
\end{tabular}

Patient 2 


\section{Cover Quizlet}

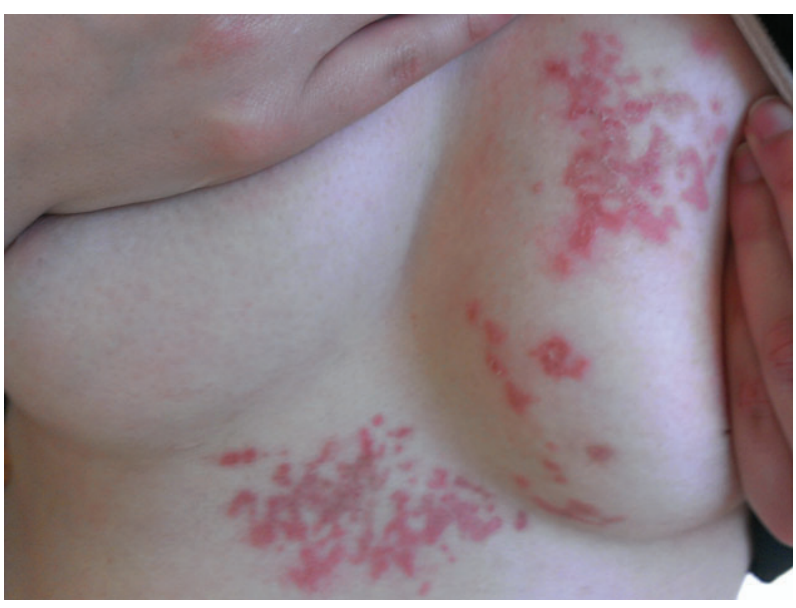

Fig. 1. Erythematous, raised clustered and reticulated papules on the chest of Patient 1.

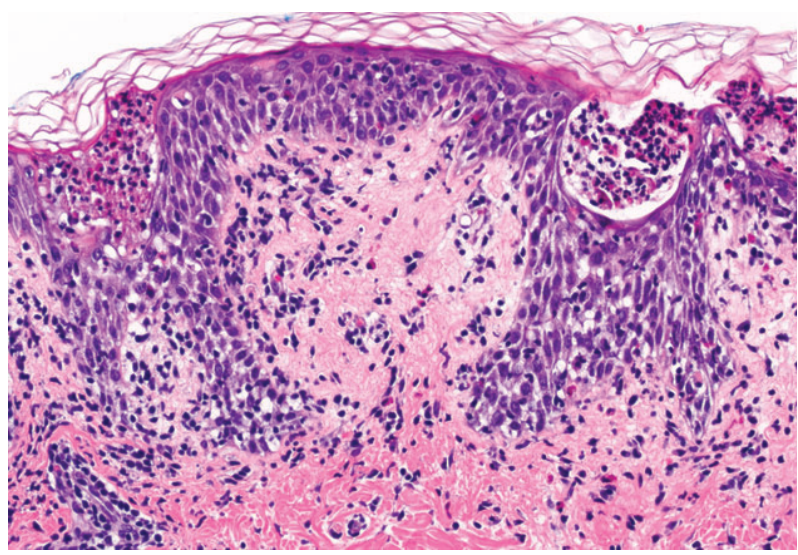

Fig. 2. Biopsy specimen from a relatively "early" lesion of Patient 1 showing diffuse epidermal spongiosis, lymphocytic exocytosis, and subcorneal collections of neutrophils. The upper dermal infiltrate is comprised of lymphocytes, neutrophils, and a few eosinophils.

these associations may merely be coincidental rather than causative. ${ }^{1,5,12-15}$ Ilkovitch and Patton recently posited PP might represent an inflammatory variant of confluent and reticulated papillomatosis, ${ }^{16}$ but that hypothesis is not supported histologically and those conditions are quite distinct.

Most patients with PP experience spontaneous resolution, followed by recurrent episodes of exacerbations that can last months to years. ${ }^{1,9,11}$ The condition responds well to minocycline, doxycycline and dapsone, presumably due to the anti-inflammatory properties of these medications, as well as inhibition of the migration and function of neutrophils. ${ }^{1,5,9,18,19}$ Yet notably, the condition does not respond to treatment with corticosteroids or anti-histamines. ${ }^{1,5}$ Lastly, there has been one report of 2 patients who responded well to weekly Jessner's peels and irradiation with an 830-nm light emitting diode. ${ }^{20}$

In conclusion, although PP is an uncommon inflammatory dermatoses it can be readily recognized by its distinctive clinicopathological features. Awareness of the dynamic changes that occur over the course of the eruption is essential to make an accurate diagnosis.

Fig. 3. Close-up view of Figure 1 which better demonstrates the reticulate pattern and overlying focal scaling and crusting.

Fig. 4. Biopsy of an evolving lesion from Patient 1 showing a normal basket weave stratum corneum overlying a mildly spongiotic epidermis. Within the superficial dermis there is a sparse perivascular superficial lymphocytic infiltrate associated with moderate papillary dermal edema.

Fig. 5. A fully developed lesion from Patient 1 showing a moderately dense perivascular and interstitial mixed inflammatory infiltrate composed of lymphocytes, neutrophils and rare eosinophils. The inflammatory infiltrate extends into the overlying epidermis which exhibits a combination of balloon degeneration and spongiosis associated with clusters of necrotic keratinocytes.

Fig. 6. Reticulated erythematous and hyperpigmented plaques on the chest of Patient 2.

Fig. 7. Patient 2 showing mature erythematous papules on the left flank and right lateral buttock as well as late hyperpigmented reticulated plaques on the sacrum.

Fig. 8. Biopsy from a relatively "mature" erythematous papule from the buttock of Patient 2. Massive spongiosis and lymphocytic exocytosis has progressed to reticular degeneration of the upper epidermis. The dermal infiltrate is moderately dense and composed of perivascular lymphocytes.

Fig. 9. A relatively "late" lesion from the sacrum from Patient 2. There is parakeratosis, focal necrotic keratinocytes, vacuolar interface alteration, and a predominantly lymphocytic upper dermal infiltrate. In such "late" lesions, upper dermal pigment incontinence is often found. 


\section{Cover Quizlet}

\section{References}

1. Böer A, Misago N, Wolter M, Kiryu H, Wang XD, Ackerman AB. Prurigo pigmentosa: a distinctive inflammatory disease of the skin. Am J Dermatopathol 2003; 25: 117.

2. Maan HS, Scott G, Mercurio MG. A pruritic, reticulated bullous eruption in a healthy young man. JAMA Dermatol 2014; 150: 1005 .

3. Micahels JD, Hoss E, DiCaudo DJ, Price H. Prurigo Pigmentosa after a strict ketogenic diet. Pediatr Dermatol. 2015; 32: 248-51

4. Jonak C, Riedl E. An itchy rash in a young Caucasian woman. Dermatol Pract Concept 2012 31; 2: 203.

5. Whang T, Kirkorian Y, Krishtul A, Phelps R, Shim-Chang H. Prurigo pigmentosa: Report of two cases in the United States and review of the literature. Dermatol Online J. 2011 15; 12: 2.

6. Roehr P, Paller AS. A pruritic eruption with reticular pigmentation. Prurigo pigmentosa. Arch Dermatol. 1993; 129: 367, 370 .

7. Joyce AP, Horn TD, Anhalt GJ. Prurigo pigmentosa report of a case and review of the literature. Arch Dermatol 1989; 125 . 1551.
8. Böer A, Ackerman AB. Prurigo pigmentosa is distinctive histopathologically. Int J Dermatol 2003; 42: 417

9. Shin JW, Lee SY, Lee JS, Whang KU, Park YL, Lee HK. Prurigo pigmentosa in Korea: clinicopathological study. Int J Dermatol 2012; 51: 152.

10. Lin SH, Ho JC, Cheng YW, Huang PH, Wang CY. Prurigo pigmentosa: a clinical and histopathologic study of 11 cases Chang Gung Med J 2010; 33: 157

11. Kim JK, Chung WK, Chang SE, Ko JY, Lee $\mathrm{JH}$, Won CH, Lee MW, Choi JH, Moon KC. Prurigo pigmentosa: clinicopathological study and analysis of 50 cases in Korea. J Dermatol. 2012; 39: 891-7. Epub 2012 Aug 20.

12. Leone L, Colato C, Girolomoni G. Prurigo pigmentosa in a pregnant woman. Int J Gynaecol Obstet 2007; 98: 261.

13. Lu PH, Hui RC, Yang LC, Yang CH, Chung WH. Prurigo pigmentosa: a clinicopathological study and analysis of associated factors. Int J Dermatol 2011; 50: 36.

14. Dijkstra JW, Bergfeld WF, Taylor JS, Ranchoff RE. Prurigo pigmentosa. A persistent lichenoid reaction to bismuth? Int J Dermatol 1987; 26: 379
15. Cho Y-T, Liao Y-H. Prurigo pigmentosalike persistent papules and plaques in a patient with Adult-onset Still's disease. Acta Derm Venereol 2014; 94: 102.

16. Ilkovitch D, Patton TJ. Is prurigo pigmentosa an inflammatory version of confluent and reticulated papillomatosis? J Am Acad Dermatol 2013; 69: e193.

17. Böer A, Asgari M. Prurigo pigmentosa: An underdiagnosed disease? Indian J Dermatol Venereol Leprol 2006; 72: 405.

18. Matsumoto C, Kinoshita M, Baba S, Suzuki H, Kanematsu S, Kanematsu N. Vesicular prurigo pigmentosa cured by minocycline. J Eur Acad Dermatol Venereol 2001; 15: 354.

19. Kim TI, Choi JW, Jeong KH, Shin MK, Lee MH. Pustular prurigo pigmentosa treated with doxycycline. J Dermatol 2016 DOI: 10.1111/1346-8138.13307. (Epub ahead of print).

20. Choi JR, Kin JK, Won CH, Lee MW, Oh ES, Chang S. Prurigo pigmentosa treated with Jessner's peel and irradiation with an 830-nm light emitting diode. J Dermatol 2012; 39: 493. 